\title{
TRACKING DISTORTIONS IN HOLISTIC MAINTENANCE MEASURES: A FRAMEWORK
}

\author{
S.A. Oke ${ }^{1}$ and A.E. Oluleye ${ }^{2}$ \\ ${ }^{1}$ Department of Mechanical Engineering \\ University of Lagos, Nigeria \\ sa_oke@yahoo.com \\ ${ }^{2}$ Department of Industrial and Production Engineering \\ University of Ibadan, Nigeria \\ aoluleye@ui.edu.ng
}

\begin{abstract}
Research on maintenance performance is seemingly well advanced in many domains. Traditional measures such as productivity, efficiency and effectiveness have many limitations that make them less applicable in today's complex industrial environments; they do not provide a balanced viewpoint of maintenance system performance when treated in isolation. This paper presents a current challenge in the field of maintenance performance measurement (MPM) namely the problems associated with holistic measures using the nominal group technique (NGT). It outlines a measurement scheme that aids the evaluation of the maintenance function and proposes a template for developing a maintenance performance index given a set of measures. The template helps in minimising the shortcomings usually brought about by implicit redundancies and overemphasis of the component measures.
\end{abstract}

\section{OPSOMMING}

Daar is getuienis dat navorsing oor die effektiwiteit van instandhouding vooruitgaan. Bekende maatstawe soos produktiwiteit, rendement en effektiwiteit skiet tekort vir hedendaagse komplekse industriële omgewings omdat hulle in isolasie nie 'n gebalanseerde beeld van instandhoudingsvertoning gee nie. Hierdie navorsing behandel die meting van instandhoudingsvertoning op 'n holistiese wyse deur gebruik te mak van die nominale groeptegniek. Dit beskryf 'n meetstelsel vir die bepaling van 'n indeks vir instandhoudingsvertoning. Tekortkominge wat voortspruit as gevolg van implisiete oortolligheid en oorbeklemtoning van komponentwaardes word geminimiseer by wyse van vereenvoudiging.

\footnotetext{
${ }^{1}$ The author was enrolled for the PhD program at the Department of Industrial Engineering, University of Ibadan, Nigeria
} 


\section{INTRODUCTION}

Maintenance performance has been a popular research field over the last 20 years. Recently, significant attention has been devoted to its theoretical and empirical scrutiny $[1,6]$. The impetus for much of this activity could be traced to the heightened competition among world class manufacturers requiring continuous improvement of manufacturing operations in order to compete successfully in a global environment. Also, the expectation that measuring the performance of systems could aid improved planning and promote the quality of decision making in the maintenance function has driven this interest. Consequently, proliferation of research articles has led to a fresh appreciation of the concepts and theories of maintenance performance. Research on maintenance performance is founded on the notion that maintenance influences organisational performance. Today, this notion has both conceptual appeal and empirical support.

The use of surrogates has been one of the most dominant approaches in studying and implementing maintenance performance measures. A wide practice is the use of single indices to depict the performance of maintenance systems. Corder (1974) first found empirical support for this prescription (see [2]). Subsequent studies, however, have uncovered results that seriously question its adequacy (e.g. [3,4]). Maintenance performance research has traditionally defined performance by indices such as labour efficiency, maintenance cost, breakdown workload, etc. Each of these measures, however, captures only one dimension of performance. Given the pitfalls of employing traditional measures of maintenance performance, its holistic measurement offers a worthwhile application [5].

It is increasingly clear that in order to understand maintenance performance measurement methodologies one must study the individual measures and the interaction between the component variables. Maintenance performance has several specific areas: observation, goal setting, reinforcement, punishment or reprimand. Thus, investigations into their interactions have altered many of the notions about choices of measures, and the methodology of composing them. One important finding is that the link between interacting variables of maintenance performance measures produce some seemingly cycling effects which can be christened duplicity or overemphasis of measures.

The interacting variables may contain surrogate measure groups representing certain aspects of the system being studied. For example, the Priel measurement group consists of three main subgroups - operations of the maintenance department, service assessment and expense justification. In combining measures from each group, earlier researchers have proposed a balanced choice of measures so as to have a representation that connotes the true state of system performance. This paper treats one of the challenges in the maintenance performance measurement field - overcoming duplicity or overemphasis of measures. Another purpose has been to present a framework that serves as a guide in composing maintenance performance measures. Templates are developed to establish a component duplicity or overemphasis avoidance strategy. Based on this, a mirror against which selected measures could be viewed and compared evolved.

\section{A MODEL FOR COMPOSING MAINTENANCE PERFORMANCE}

The goal of this section is to discuss the Normative Performance Measurement Model 
(NPMM) which is based on the normative decision science framework. The model is 3phased (see the schematic diagram below).

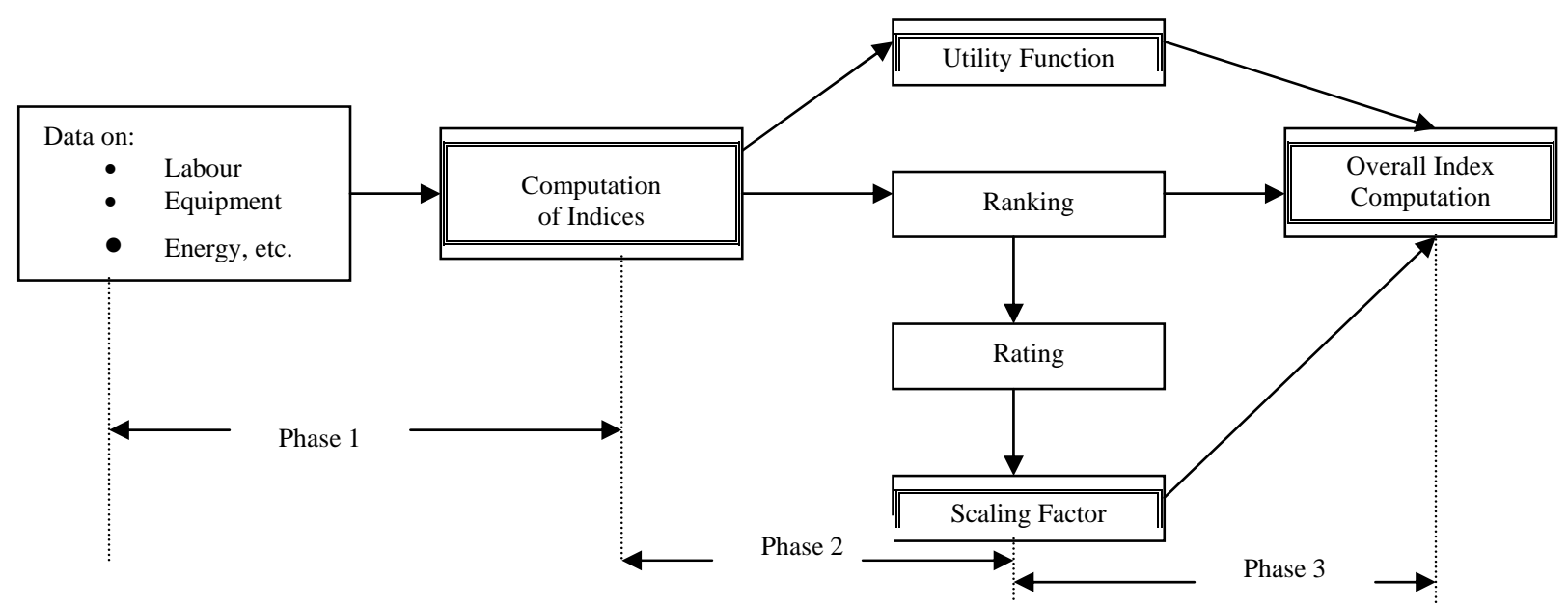

Figure 1: Schematic representation of NPMM

The first phase involves selection and computation of performance indices. This is carried out by applying the various performance ratios. In considering the treatment model 1 as the Priel's group of measures, the number of indices to be calculated is twenty. After obtaining results from the first phase of the calculation, the second phase involves four measurement activities - rating, ranking, scaling factor determination and computation of utility function. The final phase involves the determination of the overall index. This is the final computation exercise. The first stream of measures consists of twenty group members. This was developed by Priel, and shown in the tables below:

Manpower Efficiency (ME)

Incentive Coverage (IC)

Craft Hour Utilisation (CU)

Work Order Turnover (WT)

Completion Delay (CD)

Cost of Maintenance Hour (CMH)

Departmental Overhead (DO)

\section{Manpower Utilisation}

Total Man-hours allowed on jobs

Total Man-hours Worked

Man-hours on bonus

Total Direct Hours Available

Total Craft Hours Worked

Total Craft Hours Clocked

Work Order Progress

Number of Jobs Completed

Total Number of Jobs Handled

Job Weeks of delays

Number of Jobs Handled

Total Maintenance Cost

Total Direct Maintenance Hours Applied

Total Overhead Cost

Total Maintenance Expenditure

Table 1(a): Group 1: Operations of the maintenance department 


\begin{tabular}{|c|c|}
\hline \multicolumn{2}{|c|}{ Plant and Equipment Performance } \\
\hline \multirow[t]{2}{*}{ Downtime Due to Maintenance (DM) } & Total Downtime for Service \\
\hline & Total Shift Hours Worked \\
\hline \multirow[t]{2}{*}{ Breakdown Frequency (BF) } & Units Produced or Hours Worked \\
\hline & $\overline{\text { Number of Breakdowns }}$ \\
\hline \multicolumn{2}{|l|}{ The Amount of Service } \\
\hline \multirow[t]{2}{*}{ Maintenance to Production Ratio (MP) } & Total Maintenance Direct Hours \\
\hline & Total Direct Production Hours \\
\hline \multirow[t]{2}{*}{ Maintenance of Mechanisation (MM) } & Total Clocked Maintenance Hours \\
\hline & Total Av. Connected Horsepower \\
\hline \multirow[t]{2}{*}{ Maintenance Cost Components (MCC) } & Total Maintenance Expenditure \\
\hline & Number of Units Produced \\
\hline \multicolumn{2}{|l|}{ Degree of Planning } \\
\hline \multirow[t]{2}{*}{ Routine Service Workload (RSW) } & Total Hours in Regular Service \\
\hline & Total Direct Applied Maintenance Hours \\
\hline \multirow[t]{2}{*}{ Breakdown Workload (BW) } & Total Hours Spent in Br. Repairs \\
\hline & Total Clocked Maintenance Hours \\
\hline \multirow[t]{2}{*}{ Cost of Scheduled Service (CS) } & Cost of Schedules Services \\
\hline & Total Production Costs \\
\hline \multirow[t]{2}{*}{ Cost of Spares and Supplies (CSS) } & Total Cost of Spares and Supplies \\
\hline & Total Maintenance Expenditure \\
\hline \multirow[t]{2}{*}{ Maintenance Cost on Investment (MCI) } & Total Maintenance Expenditure \\
\hline & Total Investment Value \\
\hline
\end{tabular}

Table 1(b): Group 2: Service assessment

\begin{tabular}{ll}
\hline Cost Reduction Efforts (CRE) & Routine Services Workload \\
Maintenance Intensity (MI) & Mast of Maintenance Hours \\
Overall Rate of Expenditure (ORE) & $\begin{array}{l}\text { Hp per Direct Production Worker } \\
\text { Maintenance Cost Component }\end{array}$ \\
\hline
\end{tabular}

Table 1(c): Group 3: Expense justification

These surrogate measures are grouped into three (operations, service assessment and expense justification). It consists of five sub-groups (manpower utilization, work-order progress, plant and equipment performance, degree of planning and amount of service). Being ratios, each of these has expressions for both the numerator and denominator. In composing the overall (holistic) MP measure, it is common to observe repetition or over-emphasis of measures. The basic problem solved here, is how repetition or over-emphasis can be eliminated such that misinterpretation of system performance does not result.

The Nagajika's measures could be summarized as follows. In its original form, it could be broadly classified into two groups - effectiveness and efficiency measures. The effectiveness 
measures consist of four main variables namely - availability, net operating rate, operating speed rate and quality rate. The total sub-components of all these four measures are seven, namely - downtime, loading time, output, actual cycle time, operating time, theoretical cycle time and number of good products. These are expressed as both numerator and denominator. On the other hand, efficiency consists of two component variables, which are net operating rate and operating speed rate. These consist of a total number of four sub-components expressed as numerator and denominator. The sub-components are - output, actual cycle time, operating time and theoretical cycle time.

\section{Model building}

Irrespective of the treatment method considered here, the fundamental model framework remains the same. Generally, the conceptual basis for the model building is the normative group technique framework (NGT). NGT is one of the amazing decision science tools that evolved some two decades ago. The technique is characterized by the use of structural group approach to problem identification and solution geared toward free generation of ideas by diverse but relevant personnel or the issue of concern.

NGT is a new star in the MP research horizon. The honour of the application of this great decision science tool goes to F.O. Olorunniwo in 1997. In its applied form, it has a six-step approach in MP research. [3] Redefined this approach with particular attention to step II of the procedure. They commented that in implementing step I, the facilitator must guide the members of the nominal group in avoiding cycling effects. Also, only measures, which cover the broad areas relevant to the system, should be utilized. In particular, any redundant/overemphasised measure or factor should be expunged and replaced by another measure belonging to the same broad category. This is done repeatedly until redundancies/overemphasis is minimized [3].

In numerical terms, the detailed steps outlined above and the procedure for measuring performance and instituting a corrective action needed for improvement is as follows. The first phase involves obtaining and ranking the performance measures in order of decreasing importance. In a situation where the number of performance measures is $n$, the best of these individual measures is ranked 1 while the next may be ranked 2. Consequently, the third best measure is ranked 3. This ranking procedure continues until the least important measure is ranked $\mathrm{n}$, The best and worst performance for each measure is then considered over a chosen span of time.

In attending to this, the goal of each of these measures has to be borne in mind. For example, minimisation or maximisation of indices. This may be expressed as maximization of efficiency, utilization and minimization of cost and downtime. In view of this, the utility values of 1.0 and 0 are then assigned to the best and worst ranked measures respectively. The next phase involves the allotment of utility values to intermediate values within the range of 1.0 and 0 . The NGT members carry this out. Utility curves are developed using the allotted values for each measure. Also, the NGT members allot weighting factors to ranked measures such that, 
Where

$$
\text { If } \quad \mathrm{R}_{1}<\mathrm{R}_{2} \text { then } \mathrm{W}_{1}>\mathrm{W}_{2}
$$

$\mathrm{R}_{\mathrm{i}}=$ rank of performance measure $\mathrm{i}$;

$\mathrm{W}_{\mathrm{i}}=$ weight allotted to performance measure $\mathrm{i}$

The weighting factor indicates the degree of the importance of a measure in relation to the set objective. Also, scaling factors for the measures are obtained by using the relationship

$$
\mathrm{U}_{\mathrm{i}}=\mathrm{W}_{\mathrm{i}} /\left[\mathrm{W}_{1}+\mathrm{W}_{2}+\ldots+\mathrm{W}_{\mathrm{n}}\right] ; \quad \mathrm{i}=1,2, \ldots, \mathrm{n}
$$

$\mathrm{K}_{\mathrm{i}}=$ scaling factor for measured;

$\mathrm{n}=$ number of performance measures used in composing index.

Scaling factors are necessary in order to normalize the composite index. In the computation of an overall effectiveness index, target values are obtained for each measure. Target values represent expectation. The target utility values are determined using the utility curves developed. The contribution of a measure to the composite target index is given by:

$$
\mathrm{C}_{\mathrm{i}}=\mathrm{U}_{\mathrm{i}} \times \mathrm{K}_{\mathrm{i}}
$$

Where $\quad \mathrm{C}_{\mathrm{i}}=$ contribution of performance measured to the target index;

$\mathrm{U}_{\mathrm{i}}=$ utility value of target for performance measure $\mathrm{i}$;

$\mathrm{K}_{\mathrm{i}}=$ scaling factor for performance measure $\mathrm{i}$.

The composite target index, $\mathrm{T}$ is given by:

$$
\mathrm{T}=\left(\mathrm{C}_{1}+\mathrm{C}_{2}+\ldots+\mathrm{C}_{\mathrm{n}}\right)
$$

\section{TRACKING DISTORTIONS - CASES}

Clearly, there are three possible ways in which the holistic MP index could be distorted. Table 2 shows these possibilities.

Case 1 The numerator of one measure is the same as the denominator of the other (NSD)

Case 2 The numerator of one measure is the same as the numerator of the other (NSN); or, the denominator of one measure is the same as the denominator of the other (DSD)

Case 3 A whole measure is part of another measure (WPO)

\section{Table 2: Possible Cases of Distortions in the Holistic Index Formulation}

The aim was to identify all the possible cases of distortions in the group of measures usually credited to Priel. For ease of computation and as a research strategy, the paper considers four different groupings for this group of measures - (a) operations of the maintenance department (b) assessment of service (c) expense justification (d) overall grouping

Case 1-NSD: The first group of measures has a total number of seven items. Measures in this category are manpower, efficiency, incentive coverage, craft-hours utilization, work-order 
turnover, completion delay, cost of maintenance hour and departmental overhead. The expression for each of these measures is compared within the group to observe any repetition of NSD. The summary is presented in the following table.

\begin{tabular}{|c|c|c|c|c|c|c|c|}
\hline \multirow[b]{2}{*}{$\mathrm{ME}$} & $\mathrm{ME}$ & IC & $\mathrm{CU}$ & WT & CD & $\mathrm{CMH}$ & DO \\
\hline & - & & & & & & \\
\hline IC & & - & & & & & \\
\hline CU & & & - & & & & \\
\hline WT & & & & - & & & \\
\hline CD & & & & & - & & \\
\hline $\mathrm{CMH}$ & & & & & & - & NSD \\
\hline DO & & & & & & NSD & - \\
\hline
\end{tabular}

Table 3: Operation of the Maintenance Department

Distortion Matrix (group 1)

\begin{tabular}{|c|c|c|c|}
\hline \multirow{4}{*}{$\begin{array}{l}\text { CRE } \\
\text { MI } \\
\text { ORE }\end{array}$} & CRE & MI & ORE \\
\hline & - & & \\
\hline & & - & \\
\hline & & & - \\
\hline
\end{tabular}

Table 4: Expense justification

Distortion template (group 3)

\begin{tabular}{|c|c|c|c|c|c|c|c|c|c|c|}
\hline & DT & $\overline{\mathrm{BF}}$ & RSW & BW & MP & $\mathrm{MM}$ & MCC & CS & CSS & MCI \\
\hline DT & - & NSD & & & & NSD & & & & \\
\hline $\mathrm{BF}$ & NSD & - & & & & & NSD & & & \\
\hline RSW & & & - & & NSD & & & & & \\
\hline BW & & & & - & & NSD & & & & \\
\hline MP & & & NSD & & - & & & & & \\
\hline MM & NSD & & & NSD & & - & & & & \\
\hline MCC & & NSD & & & & & - & & NSD & \\
\hline CS & & & & & & & & - & & \\
\hline CSS & & & & & & & NSD & & - & \\
\hline MCI & & & & & & & & & & - \\
\hline
\end{tabular}

Table 5: Assessment of Service

Distortion Template (group 2)

A close look at the template reveals that it has line symmetry along the left diagonal. Hence, it is observed that interpretations are doubled on both sides of this line of symmetry. So only one part of this duplication is useful for the analysis. Since this relationship is duplicated along the left diagonal, only one repetition exists. By applying the same procedure for assessment of service, the distortion framework in Table 5 applies.

This is the second group of the measures containing ten measures. Measures in this category are equipment availability, downtime due to maintenance, breakdown frequency, routine services workload, breakdown workload, maintenance to production ratio, maintenance of 
mechanization, maintenance cost component, cost of scheduled services, cost of spares and supplies and maintenance cost on investment. Each member of the group is critically analysed to observe any possible repetition of measures within the group. In all, eight repetitions are observed. This repetition is symmetrical along the left diagonal of the matrix as indicated in group one also. This group exhibits a relatively high chance of being involved in repeated occurrences.

The third group consists of three measures namely cost reduction efforts, maintenance intensity and overall rate of expenditure. It appears that no repetition occurs in this group, hence the repetition matrix is as shown in Table 4. When all the groups (operations, service assessment and expense justification) are put together, eight repetitions are observed and these are repeated along the line of symmetry (see Table 6). Since the last framework as in Table 6 contains all twenty measures, it is suggested for use in any attempt to eliminate distortions since it offers a global picture of the relationships between all measures in the set.

GROUP 1

GROUP 2

GROUP 3

\begin{tabular}{|c|c|c|c|c|c|c|c|c|c|c|c|c|c|c|c|c|c|c|c|c|}
\hline \multirow{3}{*}{$\begin{array}{l}\text { ME } \\
\text { IC }\end{array}$} & $\mathrm{ME}$ & IC & $\mathrm{CU}$ & WT & CD & CMH & DO & DT & $\mathrm{BF}$ & RSW & BW & MP & MM & MCC & $\mathrm{CS}$ & CSS & MCI & CRE & MI & ORE \\
\hline & - & & & & & & & & & & & & & WPO & & & & & & \\
\hline & & - & & & & & & & & & & & & & & & & & & \\
\hline CU & & & - & & & & & & & & & & & & & & & & & \\
\hline WT & & & & - & & & & & & & & & & & & & & & & \\
\hline CD & & & & & - & & & & & & & & & & & & & & & \\
\hline $\mathrm{CMH}$ & & & & & & - & NSD & & & & & & & & & & & WPO & & \\
\hline DO & & & & & & NSD & - & & & & & & & & & DSD & & & & \\
\hline DT & & & & & & & & - & NSD & & & & NSD & & & & & & & \\
\hline $\mathrm{BF}$ & & & & & & & & NSD & - & & & & & NSD & & & & & & \\
\hline RSW & & & & & & & & & & - & & NSD & & & & & & & & \\
\hline BW & & & & & & & & & & & - & & NSD & & & & & & & \\
\hline MP & & & & & & & & & & NSD & & & & & & & & & & \\
\hline MM & & & & & & & & NSD & & & NSD & & & WPO & & & & & & \\
\hline MCC & WPO & & & & & & & & NSD & & & & WPO & & & NSD & & & & \\
\hline CS & & & & & & & & & & & & & & & & & & & & WPO \\
\hline CSS & & & & & & & DSD & & & & & & & NSD & & & & & & WPO \\
\hline MCI & & & & & & & & & & & & & & & & & & & & \\
\hline CRE & & & & & & WPO & & & & & & & & & & & & & & \\
\hline MI & & & & & & & & & & & & & & & & & & & & \\
\hline ORE & & & & & & & & & & & & & & & WPO & WPO & & & & \\
\hline
\end{tabular}

Table 6: Complete framework

\section{ANALYTICAL METHOD}

The various cases of possible distortions are illustrated as for the treatment method 1 .

Case 1- NSD: A manufacturing company requiring periodic appraisal of maintenance performance has selected the following measures using NGT.
$\mathrm{MP}=$ Total maintenance direct hours Total direct production hours
$\mathrm{MM}=$ Total clocked maintenance hours Total connected horsepower
MCC $=$ Total maintenance expenditure Number of units produced
CSS $=$ Total cost of spares and supplies Total maintenance expenditure

Two main weaknesses were observed in the measures selected. 
(i) The measures chosen were picked from one major group i.e. service assessment. In this case, there seems to be a non-uniform representation of the other aspects of the maintenance function. As an example, measures in the grouping of operations of the maintenance department and expense justification appear to be missing.

(ii) The presence of distortions is in the form of NSD. The concerned measures are Maintenance Cost Component and Cost of Spares and Supplies. Note that Total Maintenance Expenditure is a common factor for both. It appears as a numerator of Maintenance Cost Component as well as a denominator in Cost of Spares and Supplies.

Case 2- NSN: The management of a manufacturing outfit has made it a policy to utilize the following measures for developing the composite maintenance measures.
$\mathrm{ME}=$ Total man-hours allowed on jobs
Total man-hours worked on the same jobs
MCI $=\underline{\text { Total maintenance expenditure }}$ Total Investment value
MCC $=\underline{\text { Total maintenance expenditure }}$
Number of units produced
MI $=$ Maintenance/Production ratio Hp per direct production worker

\section{* Hp is Horsepower}

Observe one main weakness in this case - the presence of distortion due to NSN in the form of Total Maintenance Expenditure. Although not applicable is this case, it should be noted that another possible occurrence is DSD where a component is duplicated in the form of the denomination.

Case 3 - WPO: In a similar measurement exercise such as in case 1 and 2, the following measures were chosen by the system administrators.
$\mathrm{ME}=$ Total man-hours allowed on jobs Total man-hours worked on the same jobs
$\mathrm{RS}=$ Total hours in regular service Total direct applied maintenance hours
MI $=$ Maintenance/Production ratio Hp per direct production worker
$\mathrm{BE}=$ Units produced of hours worked Number of Breakdowns

Observe that for this case, Total Hours in Regular Services is a subset of Total Hours Worked. This is a case of WPO. In using the overall framework to develop a composite MP measure, the following steps are recommended.

1. Ensure that only one measure from each group is selected.

2. Consider all possible pairings of selected measures.

3. Find values of the composite index relating to the period of study

4. Evaluate performance relative to some standard

5. Implement corrective actions

The enumerative steps should assist in developing composite maintenance performance measures that are devoid of duplicity in their component measures, thus ensuring a balanced view of performance. 


\section{CONCLUSION}

Over the past twenty years, a large number of models have been proposed to monitor maintenance performance. This paper reviews the current primary challenges in the maintenance performance measurement field and proposed a framework that serves as a guide in composing maintenance performance measures.

The motivation for writing this article came from several sources. The main driver behind this work was the uneasy feeling that something was wrong with the present use of holistic methodology in composite model formulation. There is therefore the growing need for systematic composition of maintenance performance measures. This problem is least attended to. Thus, there is a need to create a depth of understanding necessary to improve the evaluation of the maintenance function in both production and service systems. Secondly, even though the problem of composing an integrated index using surrogate measures has been the focus of some studies, there is no documentation to show that the problem of duplicity of measures has been investigated.

In cases where the issue is raised, it has only been mentioned for further study. Thus, holistic performance measurement approach and its conceptualisation from the viewpoint of duplicity or overemphasis avoidance during composition has received little (if any) attention from scholars. Thirdly, the influence of false leads in results by means of overemphasis or redundancies could affect decision making, thus resulting in wrong decisions with possible serious consequences.

The major purpose of this paper has been to present a framework that serves as a guide in composing maintenance performance measures. A number of templates are developed and proposed. These could be used to establish a component duplicity or overemphasis avoidance strategy. Based on this, a mirror against which selected measures could be viewed and compared evolved. The performance of the framework as a guiding tool was tested with simulated data and showed attractive results. In addition, this paper articulates the multiple criticisms offered against composite model formulation when using surrogate indices for a maintenance function.

Though the computational results are very encouraging and indicate that the effect of duplicity of measures could be reduced, much more remains to be done. One potential fruitful avenue for future investigations is the possible elimination of duplicity by restructuring the measures used. Perhaps, this would be the most immediate useful follow-on study. Another attractive area for inquiry is how subjectivity could be reduced in composite formulation.

While some critical issues have been raised in this paper, a few tentative answers are offered. Rigorous empirical scrutiny of the claim will be a worthwhile investment of research efforts. Future researchers are expected to test, challenge, refine and extend the primary arguments and ideas presented here. Such efforts are critical in advancing the frontiers of knowledge in maintenance performance measurement. It will also encourage rapid proliferation of articles in this area.

Although a good deal has been learnt about maintenance performance measurement, there is 
much more to know. The present understanding is only sufficient to reveal the areas of research least explored. Consequently, one of the greatest areas for the investment of human intelligence is the study of the effects of duplicity or overemphasis on the quality of decisions made. It should also examine the magnitude of such effects on organisational performance. This is necessary for future empirical analysis of a comparative nature.

\section{REFERENCES}

[1] Paulsen, J., Cooke, R., Nyman, R., 1997, Comparative Evaluation of Maintenance Performance Using Subsurvival Functions, Reliability Engineering \& System Safety 58(2), pp. 157-163.

[2] Oke S.A. and Oluleye A.E., 1999, A Template for Composing Maintenance Performance Measures, Conference Proceedings of the Nigerian Institute of Industrial Engineers, pp. 114-125.

[3] Oluleye, A.E., Tade A.O. and Olajire K.A., 1997, A Schema for Assessing Maintenance Effectiveness, $7^{\text {th }}$ International Management of Industrial Reliability and Cost Effectiveness Symposium, University of Exeter, United Kingdom, pp. 331 - 341.

[4] Oluleye, A.E. and Gbadebori S.O., 2000, Maintenance System Evaluation: Case of a Food Company, Conference on Performance Measurement 2000 - Past, Present and Future, Cambridge, England.

[5] Tsang, A.H.C., Jardine, A.K.S., and Kolodny, H., 1999, Measuring Maintenance Performance: A Holistic Approach, International Journal of Production Management, 19(7), pp. 691-715.

[6] Uday K. and Liyanage J., 2000, On the attempt to streamline Maintenance Process using a Value Based Performance Measurement System, in Maintenance Day - 2000 Seminar, Lulea, Sweden.

[7] Wireman T. 1999, Developing Performance Indicators for Managing Maintenance, TWI Press: USA. 
